\title{
THE BENEFITS OF SOCIAL NETWORK USE TO VIETNAMESE STUDENTS' LEARNING
}

\section{NGUYEN TAN DANH}

IT Lecturer, FPT University, Vietnam

\begin{abstract}
Social networking is a fairly familiar phrase that we often hear. In the era of technology development today, the use of social networking is a very normal job because of the great benefits that it brings. However, few people know that the use of social networks also requires control and smart use. In fact, the use of social media by young people today tends to be negative and has no clear purpose, which leads to them spending too much time in their lives instead of spending that time for learning and working. This paper is completed with the desire to affirm the importance of social networking, as well as the notes that young people need to overcome hidden challenging to lead a more meaningful life.

KEYWORDS: Advantages, Behavior, Disadvantages, Social Network, Young People
\end{abstract}

Received: Jun 08, 2020; Accepted: Jun 28, 2020; Published: Aug 28, 2020; Paper Id.: IJMPERDJUN2020924

\section{INTRODUCTION}

Internet is a great invention in the field of information technology. Along with that, the advent of social networks has contributed greatly to our lives becoming richer and more convenient. With great functions such as information transmission at extremely fast speed and diverse types of entertainment such as Facebook, Youtube, etc. suitable to the needs of people of all ages, different industries and specialties. especially students. However, in order to use social media in a smart and positive way to avoid depending on it, we need to clearly identify what the intended use is.

\section{LITERATURE REVIEW}

The advent of the internet has given people very practical benefits. For students, internet students are considered a huge treasure of knowledge to help them look up information for learning as well as entertainment and socializing with friends. However, the overuse of the Internet has caused many students to fall into a state of uncontrolled use. The application of system theory in social work helps social workers assess the causes and consequences of students' internet use behavior and at the same time, allows social workers to work. establish support systems to help children use the internet the most effective way [1].

Social networks are thriving in Vietnam. In particular, the main users are teenagers and students. From the survey data on 4,205 students using social media in 6 big cities, the authors pointed out that: in the social activities students often use, Facebook is the most used (accounting for 86, 6\%), with usage time ranging from 1 hour to less than 5 hours / day. Students use the social network primarily for interactive and entertainment needs, although the level of pressure from using social networks in students is not alarming, but the more students need it The higher the social network, the more likely they are to be under pressure from social work [2]. 
Up to now, 97.6\% of people have been using Facebook; In particular, most people start using Facebook at the age of junior high school and high school and often use no more than 1-2 hours a day. With many different means, Vietnamese people often use Facebook whenever they are free and at different locations [3].

Indeed, the development of computer networks brought about major changes in human life. The computer network is an extremely large information reserve with the ability to communicate quickly and accurately, which has become an important factor in the development of each individual and each country [4] .

\section{ACTUAL SITUATION OF USING SOCIAL NETWORK IN VIETNAM}

Currently, social networking is growing very strongly in Vietnam. With a variety of applications such as Facebook, Instagram, Youtube, etc. Social networking has become one of the top concerns of young people in Vietnam. The most alarming situation today is that young people increasingly depend on social networks. Typically, the images and clips of foreign idols are very attractive to young people in Vietnam. Moreover, the videos that young people find interesting and willing to spend hours a day just to watch and accidentally make you become addicted to social networks without even knowing it.

The results of the survey on student social network use showed that out of 4,247 students surveyed, up to 4,205 students (accounting for 99\%) used social networks. As such, the use of social networking among students is now common. Among them, the social network you use the most is Facebook and next is Youtube. Because Facebook is highly interactive, multilingual and early development on mobile networks, it is very suitable for students who use it [5].

In Vietnam, Facebook is a social network used by many people, especially young people. The main purpose is still entertainment after studying, working hard. Because social media has so many types of entertainment that attract young people, the time spent with family and friends is less and less, but instead is spending time with a smartphone. smart) or laptop makes relationships with people around them increasingly blurred. Besides, most of the students and students have the habit of accessing social networks, especially Facebook, in their free time, even for a few minutes or unconsciously. Thus, it can be said that young Vietnamese are increasingly abusing social networks and not yet control their usage behavior [6].

\section{THE BENEFITS AND HARMS OF SOCIAL NETWORKS}

It's undeniable that social networks bring us a lot of benefits, not to mention the money making on social networks. Because social media is extremely large, advertising or selling its products online is a method used by many people, making good videos to meet the tastes of people. The trend also contributes to great economic benefits. Moreover, social media helps us to expand the relationships that facilitate our business. In addition, entertainment is an indispensable need for people after stressful and exhausting working hours, and social networking has now become one of the top choices for people to relax and solve. radiating pressures in life [7].

Besides educational and entertainment clips, of course there will be clips with negative content affecting the thinking and orientation of young people. Moreover, in Vietnam, the typical situation of young students is that students spend a lot of time on their Idol videos and images on social networking sites. Watching too much makes them directly affected by learning and psychology [8]. Social networks put pressure on living activities, the use of social networks has a lot of negative effects on study, health deterioration, less communication with friends and reduced entertainment activities, putting pressure on self-mastery including 3 things: individuals who cannot control their desire to social networks, 
individuals who fail to try to reduce time spent on social networks and not being freed. gets the constant obsession in mind regarding social media [5].

\section{RESEARCH METHOD}

This paper is supported to complete the multiple choice questionnaire of 61 young people aged between 16 and 28 years old including high school students and university students, and recent and recent graduates. have job. The reason for choosing these objects is because you are young people and are using social networks. Therefore, the objectivity and reality of the data collected will be clearer. In addition, these locations are very convenient for collecting specific data, such as taking multiple choice papers on Drive software. Survey results are collated and analyzed after the respondents complete the questionnaires.

\section{RESULTS AND DISCUSSION}

In order to accurately identify the social network usage of young people in Vietnam, a few questions have been raised in the table below (Table 1).

Table 1: Current Youth Access to Social Media

\begin{tabular}{|l|l|l|l|l|}
\hline \multicolumn{1}{|c|}{ Content of Questions } & \multicolumn{3}{|c|}{ Total of 61 Young People } \\
\hline $\begin{array}{l}\text { 1. What do you usually do in } \\
\text { your spare time? }\end{array}$ & $\begin{array}{l}\text { go online, surf } \\
\text { the web }\end{array}$ & $\begin{array}{l}\text { reading } \\
\text { books }\end{array}$ & play sports & $\begin{array}{l}\text { Other (see movies, } \\
\text { games, etc.) }\end{array}$ \\
\hline & $57 / 61$ & $8 / 61$ & $9 / 61$ & $5 / 61$ \\
\hline $\begin{array}{l}\text { 2. How many times a day do } \\
\text { you access your social } \\
\text { networks? }\end{array}$ & 3 times & do not enter & $\begin{array}{l}\text { about } 10 \\
\text { times }\end{array}$ & uncountable \\
\hline & $13 \%$ & $0 \%$ & $18 \%$ & $68.9 \%$ \\
\hline 3. How long is each access? & $\begin{array}{l}\text { less than 30 } \\
\text { minutes }\end{array}$ & $\begin{array}{l}\text { over 30 } \\
\text { minutes }\end{array}$ & over 1 hour & Not determined \\
\hline & $27.9 \%$ & $13.1 \%$ & $18 \%$ & $41 \%$ \\
\hline
\end{tabular}

According to the statistics of 57 people who spend free time on the internet, 57 out of 61 people, it shows that the use of social networking accounts for a lot of time in the lives of young people, while reading books Or playing sports brings a lot of benefits but only a very small fraction choose in free time. In addition, other figures show that young people use social media as a hobby to spend a lot of time of the day. This will easily lead to a saturated state that negatively affects daily life such as difficulty concentrating, studying and working ineffectively (Figure 1).

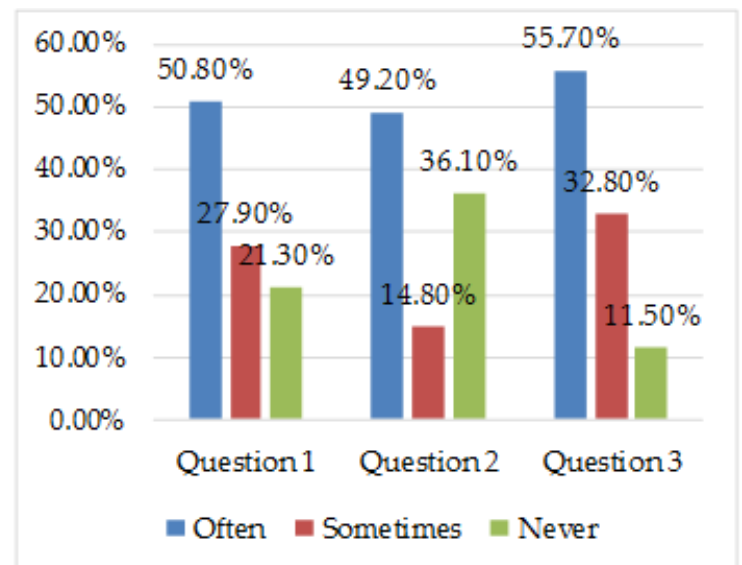

Figure 1: Dependence on Social Networks of Young People. 


\section{RECOMMENDATIONS}

First is moderation of content posted on social networks. Social networks need to be carefully censored by content to screen to remove unreliable bad information. Encourage creating positive content that propagates green, humorous but civilized lifestyles for human life. Second is to limit the time to use mobile devices.

Moreover, young people need to limit the use of smartphones, surf social networks, but instead spend time to talk more with friends to discuss learning and participating in clubs, cultural activities. healthy. Social networks will be extremely useful when people use them at the right time and for the right purpose, otherwise it will be extremely harmful when used too much [9].

Third is to select content suitable for your age. Due to the strong growth of social networks, there are countless videos and images that are posted without censorship, so when participating in social networks, young people need to know which social networking sites to choose. destination to join. Next is to create a civilized social network. In social networks will be divided into suitable groups such as business people, children, women, etc. In order to reach a community where only positive lifestyle and ideas are circulated.

Last is to create many clubs. Clubs are responsible for creating healthy playgrounds where smartphones are not used. Besides, joining the club will help young people expand relationships and improve their creativity [10].

\section{CONCLUSIONS}

Students and pupils are young and dynamic so their use of social networks is indispensable. The benefits of social networking cannot be denied by helping young people strengthen relationships, knowledge and knowledge, providing a great source of entertainment for users. However, when using social networks for the wrong purpose and not in moderation, it will cause many consequences such as indirectly affecting the psychology of users, especially young people. With the results presented above, we believe that there should be orientation for young people in using social networks in relation to time, purpose of use, as well as ways to protect themselves when participating. Join the online community.

\section{LIMITATION}

This paper has not provided a specific solution for changing the behavior of using social networks in a positive way. The simple survey method has not yet assessed all the behavior of social network users. The author hope to do it in a near future.

\section{CONFLICT OF INTERESTS}

No conflict of interests is noted in the paper.

\section{REFERENCES}

1. Ellison, N. B., Steinfield, C., \& Lampe. The benefits of Facebook “friends:" Social capital and college students' use of online social network sites. Journal of computer-mediated communication, 12(4), 1143-1168, 2007

2. Kadushin, C. Who benefits from network analysis: ethics of social network research. Social networks, 27(2), 139-153, 2005.

3. Burke, M., Marlow, C., \& Lento, T. Social network activity and social well-being. In Proceedings of the SIGCHI conference on human factors in computing systems, 1909-1912, 2010. 
4. Borgatti, S. P., Mehra, A., Brass, D. J., \& Labianca, G. Network analysis in the social sciences. science, 323(5916), 892-895, 2009.

5. Balkundi, P., \& Kilduff, M. The ties that lead: A social network approach to leadership. The leadership quarterly, 17(4), 419439, 2006.

6. Min, J., \& Kim, B. How are people enticed to disclose personal information despite privacy concerns in social network sites? The calculus between benefit and cost. Journal of the Association for Information Science and Technology, 66(4), 839-857, 2015 .

7. Hoi, H. T. Using Social Networks for English Teaching and Learning. In Proceedings of the 2019 2nd Artificial Intelligence and Cloud Computing Conference, 173-177, 2019.

8. Utz, S. The (potential) benefits of campaigning via social network sites. Journal of computer-mediated communication, 14(2), 221-243, 2009.

9. Binder, J., Howes, A., \& Sutcliffe, A. The problem of conflicting social spheres: effects of network structure on experienced tension in social network sites. In Proceedings of the SIGCHI conference on human factors in computing systems, 965-974, 2009.

10. Nguyen Thi Tinh et al., (2020). Capacity for developing training program of pedagogical universities of vietnam. International Journal of Mechanical and Production Engineering Research and Development (IJMPERD). 10 (3), $4063-4072$

11. Bizzi, L. The hidden problem of Facebook and social media at work: What if employees start searching for other jobs?. Business Horizons, 61(1), 23-33, 2018 

